\title{
Nanocellulose Bio-Nanomaterial: A Review
}

\author{
Lakshmana Prabu S* \\ Department of Pharmaceutical Technology, Bharathidasan Institute of Technology \\ Campus, Anna University, Tiruchirappalli, India
}

*Corresponding author: Lakshmana Prabu S, Department of Pharmaceutical

Technology, Bharathidasan Institute of Technology, Anna University, Tiruchirappalli, India, Tel: +919750550965;

Email: slaxmanvel@gmail.com

\section{Abstract}

Nanocellulose is a unique and gifted natural material with hierarchical structure of cellulose extracted from various natural cellulose sources like plants, animals and bacteria. Nanocellulose has gained a large amount attraction due to its remarkable properties like natural and renewable, biodegradability, biocompatibility, low cytotoxicity, high strength, modulus, high surface area, high aspect ratio, chemical functionality, dimensional stability, thermal stability, etc., Nanocellulose is available in three different types, viz cellulose nanocrystals (CNC), cellulose nanofibrils (CNF) and bacterial cellulose (BC). Due to its physical, surface chemistry and biological property it has been widely used in various biomedical applications (medical implants, tissue engineering, cardio vascular application, drug delivery), paper, packaging and electrical field. This article gives an overview about the nanocelluloses.

Keywords: Hierarchical; Cellulose; Nanocrystals; Biodegradability

\section{Introduction}

Cellulose is the most abundant linear polymer as cellulose chains occurring naturally on earth as lignocellulosic biomass. It is a high molecular weight homopolysaccharide complex having hierarchical structure. Cellulose structure is made by repeating $\beta$ (14)-bound D-glucopyranose units with a degree of polymerization of 10000 to 15000 [1]. Linear cellulose chains combined with hemicelluloses and lignin, which forms the cell walls of the wood and higher plants. Cellulose is present in higher plants, certain types of bacteria and fungi as unidirectional parallel orientation chain having one reducing end and non-reducing end [2]. Cellulose is present as two forms such as crystalline and amorphous. In crystalline region the cellulose chains are arranged as highly ordered one (made of cellular hierarchical biocomposites) and in amorphous region the cellulose chains are arranged as disordered one (made of hemicelluloses, lignin, waxes, extractive and trace elements) $[3,4]$. Presence of three hydroxyl groups in each glucose unit is the important characteristic property of the cellulose. The hydroxyl groups are present in 2, 3 and 6 positions of the glucose unit. The hydroxyl group present in the $6^{\text {th }}$ position is acts as a primary alcohol whereas the other two hydroxyl groups acts as secondary alcohol. The reactivity of the hydroxyl group are varies with its position. The hydroxyl group present in the $6^{\text {th }}$ position can react 10 times father than the hydroxyl group present in position 2 and 3; the hydroxyl group present in the position two can react twice than the hydroxyl group present in the $3^{\text {rd }}$ position $[5,6]$. Steric effect is induced in the cellulose by the attachment of the alkyl group in the hydroxyl groups. Cellulose chain is stabilized by the two types of hydrogen bonds such as intramolecular and intermolecular. In cellulose the intramolecular hydrogen bond is formed between the hydrogen borne by the $\mathrm{OH}$ group of the $\mathrm{C} 3$ carbon and ring oxygen of the adjacent glucose unit (05), whereas the intermolecular hydrogen bond is formed between the hydrogen of the OH-6 primary hydroxyl and oxygen in position $\mathrm{O} 3$ in a cycle of a neighboring unit, as well as the hydrogen of $\mathrm{OH}-2$ and oxygen in position 06 [2]. 
These hydrogen bonds are having an important role in maintaining the cellulose as hierarchical structure and increase the stiffness [7]. The hierarchical structure of cellulose [2] is shown in figure 1.

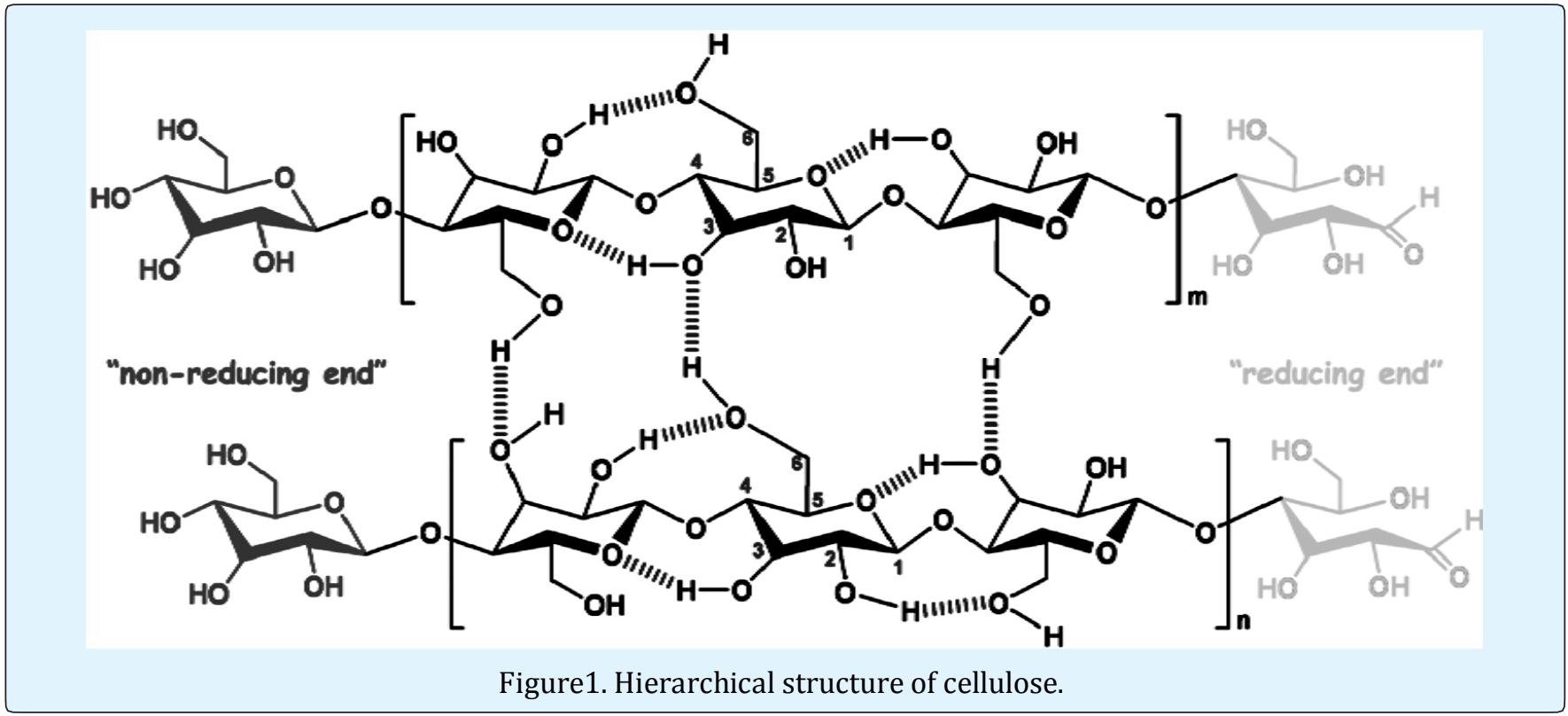

Various factors such as maturity, separating processes, microscopic and molecular defects such as pits and nods, type of soil and weather conditions under which they were grown are affect the fiber properties [4]. Nanocellulose is a product isolated from the natural cellulose which is present in the plants, animals and bacteria.

Due to its hierarchical structure and semi crystalline nature of cellulose, nanoparticles can be extracted either top-down mechanical process or chemical induced deconstructing strategy by converting the large units $(\mathrm{cm})$ into the small unit $(\mathrm{nm})$.

Nanocellulose is classified as three types. They are 1. Cellulose nanocrystals (CNC) - nanocrystalline cellulose, cellulose whiskers, nanowhiskers and nanorod

2. Cellulose nanofibrils - nanofibrillated cellulose, micro fibrillated cellulose (MFC), and cellulose nanofibers

3. Bacterial cellulose [8-9]

Cellulose nanocrystals refers to short and rigid rods; cellulose nanofibril refers to long, thread-like cellulose nanofibers and bacterial cellulose refers to ribbon-like bacterial nanocellulose (BNC).

Cellulose nanocrystals and cellulose nanofibrils can be extracted from various sources such as wood, cotton, hemp, flax, wheat straw, sugar beet, potato tuber, mulberry bark, ramie, algae and tunicin. Different nanocellulose types [2,10] are shown in Figure 2.

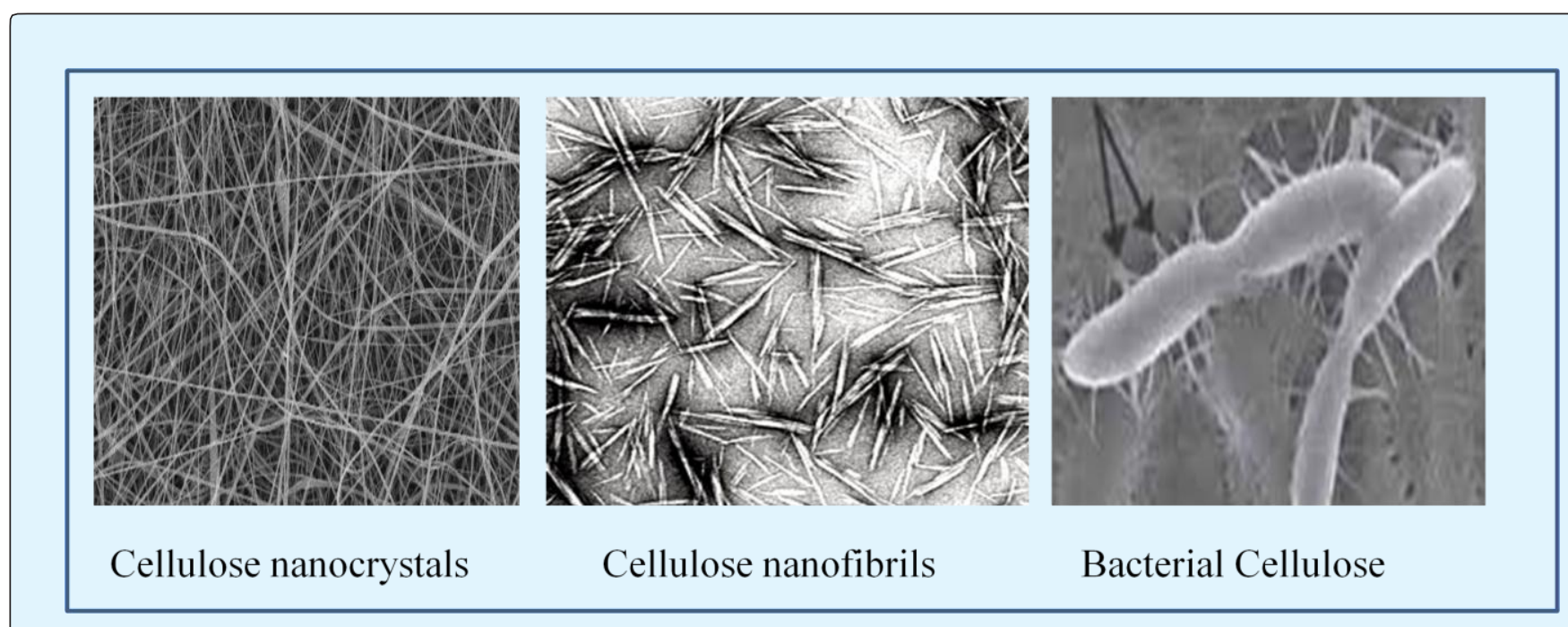

Figure2. Structure of different nanocellulose. 


\section{Bioequivalence \& Bioavailability International Journal}

\section{Isolation of Nanocellulose}

Nanocellulose as Nanocellulose fibrils can be isolated from the natural source by various mechanical process like high pressure homogenization, high intensity ultrasonication, high pressure refiner, grinding and mechanical cutting with or without post enzymatic treatment.

Nanocellulose as crystalline nanocellulose can be isolated from the natural source by chemical reaction like acid hydrolysis, enzymatic pretreatment, introduction of charged groups through carboxymethylation reaction and oxidation by 2,2,6,6tetramethylpiperidine-1-oxyl (TEMPO) [4,10-17].

\section{Mechanical Methods}

In mechanical method, multiple mechanical shearing actions are applied to the cellulosic fibers to delaminate the fiber effectively into more or fewer individual micro fibrils. The product obtained by mechanical method is not a single fiber so it is called as nanofibrils or micro fibrillated cellulose (MFC). Pre-treatment can also be done to introduce the electrostatic repulsion between the fibers and prevent the aggregation [18-21].

\section{Chemical Method}

In chemical induced destructuring method, acid hydrolysis is preferred. In acid hydrolysis method, strong acid is utilized for extraction of crystalline nanocellulose from natural cellulose by hydrolysis of the cellulose fibers, solubilizing and removal of amorphous regions and preserving the highly crystalline structure by longitudinal cutting of the micro fibrils. A range of acids such as sulphuric acid, phosphoric acid, hydrobromic acid, hydrochloric acid and nitric acid can be used for the acid hydrolysis; among the various acids sulfuric acid is preference one.

During acid hydrolysis, sulfuric acid is acting as hydrolyzing agent with the surface hydroxyl groups of the cellulose by esterification process and introducing the anionic sulfate ester group leads to form a negatively charged group induces the formation of a negative electrostatic layer on the surface of the nanocrystals. This negative electrostatic layer of the nanocrystals promotes the nanocrystals dispersion in water. The negative surface charge due to sulfate group on crystalline nanocellulose can be controlled through temperature and time duration of hydrolysis. Thermal stability of the nanocrystals prepared by acid hydrolysis method utilizing sulfuric acid can be improved by neutralization of the nanocrystals by sodium hydroxide [22-25].

\section{Mechanism of Acid Hydrolysis}

In the acid hydrolysis process, the hydronium ions from the acid penetrate the cellulose chains in the amorphous regions leads to cleavage of the hydrolytic linkage in the glycosidic bonds, leaving the crystalline segments intact. The cellulose as crystals can be released after suitable mechanical treatment [22-25].

\section{Other Methods}

Other methods for extraction of nanocrystals from native cellulose are

1. Enzymatic hydrolysis treatment

2. TEMPO oxidation

3. Hydrolysis with gaseous acid

4. Treatment with ionic liquids [4,26-29].

Bacterial Cellulose is typically synthesized by bacteria (such as Acetobacter xylinum) in a pure form which requires no intensive processing to remove unwanted impurities or contaminants such as lignin, pectin and hemicelluloses. During the biosynthesis of $\mathrm{BC}$, the glucose chains are produced inside the bacterial body and extruded out through tiny pores present on the cell envelope. With the combination of glucose chains, micro fibrils are formed and further aggregate as ribbons (nanofibers) [2, 30].

\section{Physicochemical Properties of Cellulose and Nanocellulose}

Chemically both cellulose and nanocellulose are consists of $\beta$-anhydroglucose units, these anhydroglucose units are linked together by $\beta-1-4$ glycosidic bonds. Each anhydroglucose unit have two secondary hydroxyl groups at 2, 3 and primary hydroxyl group at $6^{\text {th }}$ position.

Physically both cellulose and nanocellulose are white in color, nontoxic, biodegradable, solid homopolymer, insoluble in water, soluble in organic chemicals, having high tensile and compressive strength [2].

\section{Unique Properties of Nanocellulose Materials}

Due to its nanometer size, nanocellulose materials have some unique properties when compare to its bulk raw material (cellulose).

The unique properties of nanocellulose includes

$>$ Nanocellulose can provide extremely larger surface area to volume ratio, results to have very large surface dependent material properties.

$>$ Special morphology

$>$ Spatial confinement 


\section{Bioequivalence \& Bioavailability International Journal}

Crystallinity

Liquid crystalline behavior

Specific configuration

$>$ High surface area and energy

$>$ Large fraction of surface atoms

$>$ Lack of imperfections

$>$ Rheological properties

$>$ Mechanical reinforcement

$>$ Surface reactivity

$>$ Biocompatibility, biodegradability and low cytotoxicity [2]

\section{Mechanical Property}

Mechanical property of the nanocellulose is based on the crystalline (ordered) and amorphous (disordered) regions. In nanocellulose the amorphous region is responsible for the flexibility and plasticity whereas the crystalline region is responsible for the stiffness and elasticity of the material.

The crystallinity of the nanocellulose is determined by

$>$ Wave propagation

$>$ X-ray diffraction

$>$ Raman spectroscopy

$>$ Atomic force microscopy [2]

\section{Biocompatability and Biodegradability}

Being a natural material, nanocellulose is biocompatible whereas biodegradability concern due to lack of cellulolytic enzymes in the cellulose, it is not readily degradable but slowly degradable. The degree of degradation, absorption and immune response may be affected by its unique properties like crystallinity, hydration and swelling [2,31-33].

\section{Applications}

Various applications of nanocellulose are

\section{Biomedical}

1. Tissue bioscaffolds for cellular culture

2. Drug Excipient and drug delivery

3. Blood vessel and soft tissue substitutes

4. Skin and bone tissue repair materials

5. Antimicrobial materials

6. Medical implants

7. Tissue engineering

8. Wound-healing

9. Cardiovascular applications

10. Coating applications

\section{Others}

1. Paper and board strength enhancement
2. Porous nanocellulosic materials for insulation and packaging

3. As flocculants and retention aids

4. Rheological modifiers

5. Flexible energy storage devices (Batteries and super capacitors)

6. Adaptive, biomimetic nanocomposites [2,4,7,34-54]

\section{Conclusion}

In recent years, there has been an intense research to focus on the use of natural polymers (biomass) as a renewable energy source materials. Natural polymers are abundantly available on the variety of natural organisms with the specific properties to meet its needs in the earth. Cellulose in the plant cell wall has been considered as a basic structural matrix. Among the range of polymer materials nanocellulose has gained much attention among the researchers. Numerous availability and nanocellulose material unique properties, created a wide extended variety of applications in the different field. Among the different applications nanocellulose materials are widely utilized in the biomedical applications due to its physical stability, outstanding mechanical property, biocompatibility, low cytotoxicity, high strength, surface area, thermal stability and low degradation rate of cellulose in the human body. Certainly nanocellulose is a gift provided by nature and its biomedical application is still in its first phase. But in near future nanocellulose will provide a good solution for some of the undefeatable challenges of biomedical application field.

\section{References}

1. Moon RJ, Martini A, Nairn J, Simonsen J, Youngblood J (2011) Cellulose nanomaterials review: structure, properties and nanocomposites. Chemical Society Reviews 40(7): 3941-3994.

2. Lin N, Dufresne A (2014) Nanocellulose in biomedicine: Current status and future prospect. European Polymer Journal 59: 302-325.

3. Fengel D, Wegener G (1984) Wood: Chemistry, Ultrastructure, Reactions, Walter de Gruyter, Journal of Polymer Science Part C: Polymer Letters 23(11): 601-602.

4. Dufresne A (2013) Nanocellulose: a new ageless nanomaterial. Materials today 16(6): 220-227.

5. Wakelyn PJ (1998) In: Levin M, Pearce EM, editors. Handbook of fiber chemistry. New York: Marcel Dekker Pp: 642-654. 
6. Hebeish A, Guthrie JT (1981) The chemistry and technology of cellulosic copolymers. Berlin: Springer-Verlag 4.

7. Hua K (2015) Nanocellulose for Biomedical Applications. Modification, Characterization and Biocompatibility Studies. Digital Comprehensive Summaries of Uppsala Dissertations from the Faculty of Science and Technology, Uppsala: Acta Universitatis Upsaliensis. Pp: 80.

8. Dufresne A (2012) Nanocellulose. From nature to high performance tailored materials. Berlin/Boston: Walter de Gruyter $\mathrm{GmbH}$;

9. Klemm D, Kramer F, Moritz S, Lindstrom T, Ankerfors M et al. (2011) Nanocelluloses: a new family of nature-based materials. Angewandte Chemie International Edition 50(24): 5438-5466.

10. http://www.acceler8or.com/2012/09/4403/

11. Henriksson M, Henriksson G, Berglund A, Lindstrom $\mathrm{T}$ (2007) An environmentally friendly method for enzyme-assisted preparation of microfibrillated cellulose (MFC) nanofibers. European Polymer Journal 43(8): 3434-3441.

12. Paakko $M$, ANkerfors $M$, Kosonen $H$, Bykanen $A$, Ahola S et al. (2007) Enzymatic hydrolysis combined with mechanical shearing and highpressure homogenization for nanoscale cellulose fibrils and strong gels. Biomacromolecules 8(6): 1934-1941.

13. Wagberg L, Decher G, Norgren M, Lindstrom $T$, ANkerfors $M$ et al. (2008) The build-up of polyelectrolyte multilayers of microfibrillated cellulose and cationic polyelectrolytes. Langmuir 24 (3): 784-795.

14. Isogai A, Saito T, Fukuzumi H (2011) TEMPOoxidized cellulose nanofibers. Nanoscale 3: 71-85.

15. Borjesson M, Westman G (2015) Crystalline Nanocellulose - Preparation, Modification and Properties. In: Cellulose Fundamental aspects and current trends. Poletto $\mathrm{M}$ and Ornaghi Junior HL (editors) InTech, Croatia 159-192.

16. Chirayil CJ, Mathew L, Thomas S (2014) Review of recent research in nano cellulose preparation from different lignocellulosic fibers. Reviews on Advanced Material Science 37: 20-28.

17. Jonoobi M, Oladi R, Davoudpour Y, Oksman K, Dufresne A et al. (2015) Different preparation methods and properties of nanostructured cellulose from various natural resources and residues: a review. Cellulose 22(2): 935-969.

18. Dufresne A. Nanocellulose: From Nature to High Performance Tailored Materials. Walter de Gruyter GmbH \& Co. KG, 2012.

19. Wang S, Cheng Q (2009) A novel process to isolate fibrils from cellulose fibers by high-intensity ultrasonication, Part 1: Process optimization. Journal of Applied Polymer Science 113(2): 12701275 .

20. Chakraborty A, Sain M, Kortschot M (2005) Cellulose microfibrils: A novel method of preparation using high shear refining and cryocrushing. Holzforschung 59(1): 102-107.

21. Abe K, Iwamoto S, Yano H (2007) Obtaining cellulose nanofibers with a uniform width of $15 \mathrm{~nm}$ from wood. Biomacromolecules 8(10): 3276-3278.

22. Zhou YM, Fu SY, Zheng LM, Zhan HY (2012) Effect of nanocellulose isolation techniques on the formation of reinforced poly(vinyl alcohol) nanocomposite films. eXPRESS Polymer Letters 6(10): 794-804.

23. Loelovich M (2012) Optimal Conditions for Isolation of Nanocrystalline Cellulose Particles. Nanoscience and Nanotechnology 2(2): 9-13.

24. Liu ZM, Xie C (2012) Preparation and morphology of Nanocrystalline cellulose from bamboo pulp. Proceedings of the $55^{\text {th }}$ International Convention of Society of Wood Science and Technology August 2731, 2012 - Beijing, CHINA.

25. Bondeson D, Mathew A, Oksman K (2006) Optimization of the isolation of nanocrystals from microcrystalline cellulose by acid hydrolysis. Cellulose 13: 171-180.

26. Krishnamachari $P$, Hashaikeh $R$, Chiesa M, Rab KRMGL (2012) Effects of acid hydrolysis time on cellulose nanocrystals properties: nanoindentation and thermogravimetric studies. Cellulose Chemistry and Technology 46 (1-2): 13-18.

27. Siqueira G, Tapin-Lingua S, Bras J, Perez DS, Dufresn A (2010) Morphological investigation of nanoparticles obtained from combined mechanical shearing, and enzymatic and acid hydrolysis of sisal fibers. Cellulose 17(6): 1147-1158.

28. Hirota M, Tamura N, Saito T, Isogai A (2010) Water dispersion of cellulose II nanocrystals prepared by TEMPO-mediated oxidation of mercerized cellulose at pH 4.8. Cellulose 17(2): 279-288. 
29. Kontturi E (2011) UPM-Kymmene Corporation. Process for preparing micro-and nanocrystalline cellulose. Patent W02011/114005.

30. Man Z, Muhammad N, Sarwono A, Bustam MA, Vignesh Kumar M et al. (2011) Preparation of Cellulose Nanocrystals Using an Ionic Liquid. Journal of Polymers and the Environment 19(3): 726-731.

31. Lin S-P, Calvar IL, Catchmark JM, Liu J-R, Demirci A et al. (2013) Biosynthesis, production and applications of bacterial cellulose. Cellulose 20(5): 2191-2219.

32. Dugan JM, Gough JE, Eichhorn SJ (2013) Bacterial cellulose scaffolds and cellulose nanowhiskers for tissue engineering. Nanomedicine 8(2): 287-298.

33. Miyamoto $\mathrm{T}$, Takahashi $\mathrm{S}$, Ito $\mathrm{H}$, Inagaki $\mathrm{H}$, Noishiki Y (1989) Tissue biocompatibility of cellulose and its derivatives. Journal of Biomedical Materials Research Part A 23(1): 125-133.

34. Martson M, Viljanto J, Hurme T, Laippala P, Saukko $P(1999)$ Is cellulose sponge degradable or stable as implantation material? An in vivo subcutaneous study in the rat. Biomaterials 20: 1989-1995.

35. Jorfi M, Foster EJ (2015) Recent advances in nanocellulose for biomedical applications. Journal of Applied Polymer Science 132(14).

36. Kalia S, Dufresne A, Cherian BM, Kaith BS, Luc Av'erous et al. (2011) Cellulose-Based Bio- and Nanocomposites: A Review. International Journal of Polymer Science Article ID 837875. Pp: 35.

37. Salas C, Nypelo T, Rodriguez-Abreu C, Carrillo C, Rojas OJ (2014) Nanocellulose properties and applications in colloids and interface. Current Opinion in Colloid \& Interface Science 19: 383-396.

38. Czaja WK, Young DJ, Kawecki M, Brown RM Jr (2007) The future prospects of microbial cellulose in biomedical applications. Biomacromolecules 8(1): 1-12.

39. Bodin A, Ahrenstedt L, Fink H, Brumer H, Risberg B et al. (2007) Modification of Nanocellulose with a Xyloglucan-RGD Conjugate Enhances Adhesion and Proliferation of Endothelial Cells: Implications for Tissue Engineering. Biomacromolecules 8(12): 3697-3704.
40. Svensson A, Nicklasson E, Harrah T, Panilaitis B, Kaplan DL et al. (2005) Bacterial cellulose as a potential scaffold for tissue engineering of cartilage. Biomaterials 26(4): 419-431.

41. Helenius G, Backdahl H, Bodin A, Nannmark U, Gatenholm P et al. (2006) In vivo biocompatibility of bacterial cellulose. Journal of Biomedical Materials Research. Part A 76(2): 431-438.

42. Bodin A, Concaro S, Brittberg M, Gatenholm P (2007) Bacterial cellulose as a potential meniscus implant. Journal of Tissue Engineering and Regenerative Medicine 1(5): 406-408.

43. Backdahl H, Esguerra $M$, Delbro D, Risberg B, Gatenholm P (2008) Engineering microporosity in bacterial cellulose scaffolds. Journal of Tissue Engineering and Regenerative Medicine 2(6): 320330.

44. Fu L, Zhang Y, Li C, Wu Z, Zhuo Q et al. (2012) Skin tissue repair materials from bacterial cellulose by a multilayer fermentation method. Journal of Material Chemistry 22: 12349- 12357.

45. Wang J, Gao C, Zhang Y, Wan Y (2010) Preparation and in vitro characterization of BC/PVA hydrogel composite for its potential use as artificial cornea biomaterial. Materials Science and Engineering: C. 30(1): 214-218.

46. Petersen N, Gatenholm P (2011) Bacterial cellulosebased materials and medical devices: current state and perspectives. Applied Microbiology and Biotechnology 91(5): 1277-86.

47. Martinez H, Brackmann C, Enejder A, Gatenholm P (2012) Mechanical stimulation of fibroblasts in micro-channeled bacterial cellulose scaffolds enhances production of oriented collagen fibers. J. Biomedical Material Research Part A 100(4): 948957.

48. Malm CJ, Risberg B, Bodin A, Bäckdahl H, Johansson BR et al. (2012) Small calibre biosynthetic bacterial cellulose blood vessels: 13-months patency in a sheep model. Scandinavian Cardiovascular Journal 46(1): 57-62.

49. Ninan N, Muthiah M, Park IK, Elain A, Thomas S et al. (2013) Pectin/carboxymethyl cellulose/microfibrillated cellulose composite scaffolds for tissue engineering. Carbohydrate Polymers.98(1): 877-85. 


\section{Bioequivalence \& Bioavailability International Journal}

50. Fu L, Zhou P, Zhang S, Yang G (2013) Evaluation of bacterial nanocellulose-based uniform wound dressing for large area skin transplantation. Material Science and Engineering C Material for Biological Applications. 33(5): 2995-3000.

51. Fan L, Tan C, Wang L, Pan X, Cao M et al. (2013) Preparation, characterization and the effect of carboxymethylated chitosan-cellulose derivatives hydrogels on wound healing. Journal of Applied Polymer Science 128(5): 2789 - 2796.

52. Shi Z, Li Y, Chen X, Han H, Yang G (2014) Double network bacterial cellulose hydrogel to build a biology-device interface. Nanoscale 6(2): 970-977.
53. Dong S, Cho HJ, Lee YW, Roman M (2014) Synthesis and Cellular Uptake of Folic Acid-Conjugated Cellulose Nanocrystals for Cancer Targeting. Biomacromolecules 15 (5): 1560-1567

54. .http://www.vtt.fi/files/events/PulPaper10/NFCA pplications_HPH.pdf

55. https://tapahtumat.tekes.fi/uploads/be83a232/Lai ne_Janne-6572.pdf 